Cilt / Volume 3, Say1 / Issue 2, 2020, pp. 143-158

E - ISSN: 2636-7718

URL: https://journals.gen.tr/index.php/arts

DOİ: https://doi.org/10.31566/arts.3.011

Araştırma Makalesi / Research Article

\title{
WHAT'S IN A NAME? EXPERIMENT ON THE AESTHETIC JUDGMENTS OF ART PRODUCED BY ARTIFICIAL INTELLIGENCE
}

\author{
Khalil ISRAFILZADE* \\ * Vytautas Magnus University, LITHUANIA \\ e-mail: khalil.israfil@gmail.com \\ ORCID: https://orcid.org/0000-0001-8228-4024
}

Received: 2 February 2020; Accepted:13 May 2020

\begin{abstract}
We conducted an experiment to explore the effect on aesthetic judgments influenced by the presence and awareness of the title of the abstract paintings produced by Artificial Intelligence. Fiftytwo participants (52 students from the Faculty of Fine Arts) were randomly signed into control and experimental groups. Participants of the control group were asked to rate five abstract paintings created by various artists, while the experimental group also rated the same paintings only differing in the names of the author that they were made by Artificial Intelligence. Consequently, in our research, we adopted Berlyne's psychobiological theory, which focuses on the role of arousal as one of the primary determinants of aesthetic preference. The results suggest that the name of AI on title can function as a novelty and surprising reference to denote performance for our visual arts perception despite the fact that it is not created by AI. However, "complexity," "interestingness," and "ambiguity" variables didn't show any statistic significant. These findings extend past research by demonstrating that title presentation affects the perception of abstract art by the participants.
\end{abstract}

Key words: Artificial Intelligence, Cognitive Science, Aesthetic preference, Art Appreciation, Abstract Art. 


\section{INTRODUCTION}

We are currently faced with the rise of Artificial Intelligence (AI), which is the core part of The Fourth Industrial Revolution that mostly predictable to be driven by data analysis and AI (Schwab, 2017). This implies absolutely enormous changes in the ways of our living and working style. However, no one can say for sure that what exactly AI will reshape and take in the coming years. At present, we are on the verge of an automated transformation which is going to influence both our ordinary practices and perceptions enormously. Slowly, AI-running programs take over tasks previously performed by humans, and many tasks involving basic repetitive motions have already been fully automated. Today we have become a time of computing where systems of AI challenge the way we think (Pan, 2016). One of the biggest challenges which AI faces is the creation of the artworks that could be called as an art.

Over the past few decades, machine-generated art has enhanced its methods and expanded its toolkit to learn and rewrite algorithms capable of generating unique works of art (Chamberlain et al., 2018), most notably in the literature and film industry (Kakoudaki, 2014). Now we can see the new level of connection between AI and art through the advancement of the latest technologies. The field of computational creativity is centred around, enabling the machine to create human-level contents such as music, poems, paintings, movie or news scripts, jokes along with creative problem-solving (Elgammal \& Saleh, 2015). However, when it comes to abstract and creative activities, people continue to be dominant. As artificial intelligence software is gradually becoming a part of daily life, it is important to understand how creative activities that are considered special to human beings can be appreciated when created by a computer.

In our research, we focused on how we perceive the value of AI-generated art in our perception, in terms of our ability to evaluate aesthetics defining whether certain works of Abstract Paintings were created by the artist or AI-generated art.

\section{RELATED WORKS}

\subsection{AI-generated paintings}

Different algorithms have been suggested within the computational creativity literature to explore diverse and productive ways of discovering the creative space. If we look at the 60s, we could see AI-generated picture by Michael Noll's (member of the research staff at Bell Telephone Laboratories) research (Noll, 1966). Noll became interested in computer art accidentally when his microfilm plotter went wrong and created an odd linear model. In 1964, Michael Noll took the famous work of Mondrian ("Composition With Lines" from 1917) and wrote a computer algorithm to generate it (Appendix 1).

Moreover, today, speed and technology progress has enabled us to create tens of AIgenerated art software. The museum in Oxford held its first solo exhibition of eight paintings by "Ai-Da", a humanoid robot with artificial intelligence (Stock, 2019). Nevertheless, one of the latest researches showed that creative machines could determine not only their creativity but also the creative results of other agents (Shamir et al., 2016).

One of the sophisticated software for painting is "The Painting Fool" (Colton, 2012; Colton et al., 2015) which is described as a computer program that simulates a human painter's behavioural and cognitive components that all systems are autonomous, and technology has the ability to make decisions. One of this program's unique features is that the machine can mimic various artistic media and act as a device with brush, ink, sketch and canvas. Another example is a research team in Tübingen (Germany), which created a Convolutional Neural Network 
(CNN) capable of recreating an object in the style of famous artists such as Kandinsky and van Gogh (Gatys et al., 2016).

Alternative AI software related to paintings was generated by Creative Adversarial Networks (CAN) (Elgammal et al., 2017), as this is a visual style that seems familiar, but not the same as what we know (and probably due to the neural network's coevolutionary representations) (Hertzmann, 2018). Creative Adversarial Networks are designed to generate images that do not match the known artistic styles; thus, according to the paper, are "... maximizing deviation from existing models and minimizing deviation from art distribution" (Elgammal et al., 2017). They designed structures using sketches from the WikiArt database that was in the public domain, which includes an extensive collection from the 15th to the 20th century, using 81,449 paintings by 1119 artists. In fact, it is reasonable to assume that these works are digital creative machines that do not require direct contact, regulator, and monitoring while generating paintings.

One of these inquiries, however, went further and made a big buzz about AI in the media. The first AI-generated painting was sold at the Christie's Auctions in New York on October 25, 2018, for 432,500 US dollars -; it was expected to be sold for 10,000 USD dollars (Cohn, 2018). Thus, the portrait was generated by the Goodfellow's algorithm known as the Generative Adversarial Networks (Goodfellow et al., 2014) and trained by the "Obvious Art" group (ObviousArt, 2018). Generative Adversarial Network (GAN) is a class of machine learning systems developed in 2014 by Ian Goodfellow and his colleagues (Goodfellow et al., 2014). The generative network produces candidates while the discriminatory network evaluates them.

Following this media hype, we could initiate to understand how individuals judged this AI-generated art that was sold at a specific price. In this way, discussions and researches are still ongoing (Coeckelbergh, 2016; Steinert, 2016; Fossa, 2017; Israfilzade \& Pileliené, 2018; Hertzmann, 2018; Nunez 2019) and related to the main question "Can machine create art?".

Regardless of the quick advances in and more wide-ranging accessibility of machinegenerated art, there is not much psychological research concerning its effect on our perception. The current studies attempted to examine how audiences react to visual artworks created either by humans or machines.

\subsection{Art and Title}

The question of what individuals like and how they judge quality in art is a part of the wider question of how people judge valence-based objects in the absence of objective metrics (Eisner, 2002). Visual art is always presented within a context (Mullennix \& Robinet, 2018).

Economist William Grampp (1989) suggests in his iconoclastic book on art that an esthetic object consists of a painting, an artist, and a title. Reproductions of visual art are often accompanied by titles in print media, digital media and social networks. A famous Shakespearean quotation from Romeo and Juliet was used by art philosopher Jerrold Levinson (1985) to begin his paper: "What's in a name? That which we call a rose, by any other name would smell as sweet." and assumed that the flower's name was "rose". He also argued that:

"Titled artwork has a significant effect on the aesthetic face that it shows and on the characteristics that we identify in it correctly. A painting of a rose might very well smell differently, aesthetically speaking, by a name other than the one it has (p. 29)."

In addition, Cognitive Psychology Professor Cleeremans and his colleagues (2016) conducted research on the effect on esthetic decisions of an artist's name by also naming their 
paper "What's in a name?". It is argued that a name could alter the art work's ease of processing (Gerger \& Leder, 2015) or provide further insights into the nature of the artwork. As argued by Fisher (1984):

"While titles are names, they are a good deal more than just names. They are not necessarily descriptions, although they can contain descriptive elements. They are names for a purpose, but not merely for the purpose of identification and designation... The unique purpose of titling is hermeneutical: titles are names which function as guides to interpretation (p. 288)."

Regarding the link between titles and visual art objects, several researches have shown that the presence of visual art titles influences the affection of the observer for the artwork (Belke et al., 2010; Gerger \& Leder, 2015) and perception of the artwork itself (Leder et al., 2004; 2006; Mullennix \& Robinet, 2018). Another exciting research in this domain carried out in Croatia (Bubić et al., 2016) using eye-movement analysis showed that knowledge of the title enhanced the liking of the presented abstract paintings by the participants. On the other hand, while short descriptive titles may increase the importance of the artworks observed, it has been suggested that titles do not positively affect the hedonic assessment of the paintings displayed (Russell \& Milne, 1997).

Art knowledge of the person also plays a crucial role in consumption and appreciating art. The average comprehension levels of art experts were much higher than beginners (Leder et al., 2004; Mullennix \& Robinet, 2018). It shows that intellectual value behind the titled artworks was better understood by experts than did the novices, which is likely linked to art knowledge.

Most of the researches carried out results using abstract paintings (Alvarez et al., 2015; Nissel et al., 2015; Shamir et al., 2016; Bubić et al., 2016; Mullennix \& Robinet, 2018). Sometimes abstract paintings may be confusing to understand at first quick look, but if done correctly, they also have a profound appeal to them. Abstract Expressionism is an art school defined by non-representational paintings in which sentiment is displayed by colour, composition and brush strokes. The public also misunderstood such works as not needing any abilities and as pictures that even a child could have produced. Abstract expressionist images are completely non-representational, and recognizing abstract expressionism involves awareness according to what the authors are attempting to achieve (Varnedoe, 2006). Those who are not educated in visual art see more than they know when they look at abstract paintings of expressionism and for this reason, Hawley-Dolan and Winner (2011) concludes the research article with the expression "People see the mind behind the art."

Recent studies should help to argue that abstract expressionist paintings are identifiable from pre-school paintings for unprofessional adults (Hawley-Dolan \& Winner, 2011; Alvarez et al., 2015; Nissel et al., 2015). Observers who are unfamiliar with abstract art can differentiate paintings by the artist from paintings by children and animals that are highly similar (Nissel et al., 2015). Correspondingly, chimpanzee drawings were mistaken for "good" art (Hussain, 1965). Therefore, differences could be identified not only by adults without any knowledge of art history but also by computers. One of the latest studies (Shamir et al., 2016), the researcher tried to find out if machine perception could distinguish differences between human, child, and animal abstract paintings. They show that the computer algorithm can discriminate between abstract paintings and children's and animal's work in 68 per cent of cases. It should be remembered that in most situations, machine vision is poorer than human vision. 


\subsection{Development of hypotheses}

Aesthetic perceptions are highly complicated phenomena to study because of a variety of underlying causes. Thus, it is not unexpected that the study of empirical aesthetics has created competing views as to why people show interests for particular objects over others or why they find particular objects to be more attractive (Palmer et al., 2013; Pelowski et al. 2016). Therefore, we adopted Berlyne's psychobiological theory (Berlyne, 1960; 1971) in our research, which focuses on the role of arousal as one of the primary determining factors of aesthetic preference. The psychobiological theory of Berlyne consists of variables; (a) psychophysical variables, (b) ecological variables, and (c) collative variables, respectively. Psychophysical variables relate to noticeable variations in the characteristics of a stimulus such as intensity or loudness (e.g. stimulus intensity, stimulus quality), while ecological variables relate to prior associations and interpretations such as nostalgic memory caused by a specific stimulus. At the other hand, Berlyne $(1967,1971)$ was unable to make a compelling argument that ecological variables are related to preference. Consequently, there is also less convincing evidence that preference is linked to psychophysical variables (Martindale \& Moore, 1989). Collative variables include complexity, novelty/familiarity, change, conflict, surprisingness, uncertainty, interestingness and ambiguity (Berlyne, 1960, 1971; Chmiel \& Schubert, 2017) that he developed the term collative variables to refer to these properties collectively.

Berlyne suggested that all three types of variables would lead to aesthetic preference, and collative variables are considered to be the most significant indicators of exploratory behaviour (Berlyne, 1971, 1974). Therefore, the research of Berlyne and much of his corresponding research (Berlyne \& Ogilvie, 1974; Cupchik, 1974; Lévy, 2006) was focused in whole or part on the position of "collative variables" in aesthetic preference (Chmiel \& Schubert, 2017).

Berlyne's contribution to art psychology, called "new experimental aesthetics" (Berlyne, 1974), was an evolution of his previous concepts of curiosity and exploration (Berlyne, 1960, 1967). The concept of collative variables is an important contribution of Berlyne to the morphological study of aesthetic stimulation. Berlyne used two types of concepts; collative variables and an arousal system of reward to make assumptions about aesthetic responses to art. He believed that the collative variables were expressed in the structural characteristics of art. Such collative variables are an implicit by-product of the viewer's assessment of similarities and distinctions between stimulus elements (e.g. complexity), and also between stimulus elements and the viewer's prior knowledge (e.g. novelty) or perceptions (e.g. surprise) (Cupchik, 1986). Various art products (e.g. paintings, music, movies etc.) could be represented as differed in complexity, creativity, ambiguity, and conflict, especially when perceived as reflecting the abstract quality of knowledge. Collative variables have therefore been chosen as one of the primary determinants of aesthetic preference in our research to test the hypothesis.

Michael Noll's research "human or machine: a subjective comparison of Piet Mondrian's "composition with lines" (1917) and a computer-generated picture" was one of the ground-breaking and extraordinary works of his period, which was published in 1966. They asked to rate a random computer-generated picture with Mondrian's untitled painting, and respondents preferred the computer-generated picture more than Mondrian's work. However, when they asked to identify Mondrian's painting, respondents selected the computer image more frequently.

Interestingly, when art was branded as being from a prestigious gallery in recent research (Kirk et al., 2009), individuals found the identical image more aesthetically appealing than when it was branded as being generated by a machine. 
Furthermore, we hypothesized that:

$\mathrm{H}$ : Paintings with the Artificial Intelligence labelled as an author would have a significant impact on the participants' aesthetic preference; (a) complexity, (b) novelty, (c) surprisingness, $(d)$ interestingness, and (e) ambiguity.

\section{METHOD}

To test the hypotheses, the experimental design was chosen. All participants were students from the Tbilisi State Academy of Arts (Georgia) who were majoring from the Faculty of Fine Arts in areas related to various visual arts. Participant randomly was signed into two groups, experimental and control group. The average age of participants in the experimental group $(n=28)$ was 20.17 years $(s d=1.86)$ and in the control group $(n=24)$ was 20.42 years $(s d=1.89)$ with age range from 17 to 25 . Distribution of the gender was accordingly in the experimental group female $(n)=21$ and male $(n)=7$; the control group female $(n)=19$ and male $(n)=5$. Consequently, participants were predominantly female in both groups.

In addition to three participant profile questions, the questionnaire consisted of 25 questions that were formulated based on the related literature and divided into five groups of evaluation questions of abstract paintings.

All Abstract paintings have been chosen randomly from the public domain of the Wikimedia Commons, and none of the copyrights has been breached since only certain paintings that were approved under the license Creative Commons (CC BY-SA 4.0) have been selected (Table 1), and in the appendix (Appendix 2), we present all the links of the original works.

Table 1. List of abstract paintings

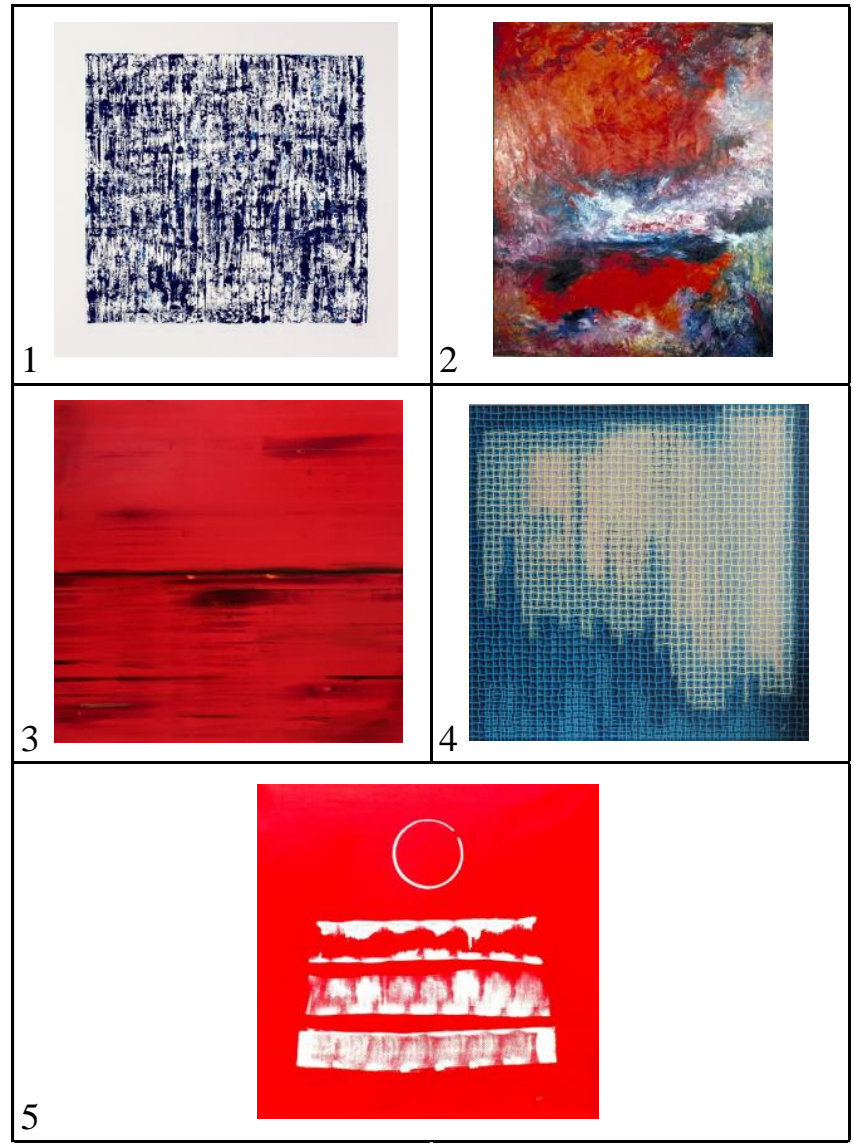

1. "Houses of the Holy VI" Painting by Stella Michaels;

2. "I Think of the Open Sea" Painting by Jon Schueler Estate;

3. "Creating Mischief" Painting by Todd Williamson;

4. Painting by Henny van Setten;

5. "Red Sea IV" Painting by Stella Michaels. 
The questions were based on the theory of Berlyne's $(1960 ; 1971)$ collative variables (Table 2). Participant in the experimental group received a false title that authors of all five paintings were Artificial Intelligence (e.g. "Houses of the Holy VI" Painting by Artificial Intelligence). Control group provided original painting details by the actual authors' names with titles (e.g. "Houses of the Holy VI" Painting by Stella Michaels). Each digitized colour abstract paintings were accompanied by the title. The seven-point Likert scale question was chosen to gather more comprehensive responses. Seven-point Likert scales are sufficiently sensitive to obtain a more accurate assessment of respondents and are more suitable for the distribution of physical paper survey (Finstad, 2010).

Each of the questions was answered on a seven-point Likert scale from Strongly Agree to Strongly disagree (Strongly Agree, Agree, Somehow Agree, Neutral, Somehow Disagree, Disagree, and Strongly Disagree) or rating scale. Participants completed a paper and pencil version of the survey questionnaire evaluating the paintings' aesthetics. For data analysis and testing hypotheses, the SPSS statistical program was chosen. None of the participants showed familiarity with viewed abstract paintings.

\subsection{Experiment}

For the questionnaire, measurement scales are developed from Berlyne's $(1960 ; 1971)$ research on the respectively collative variables; complexity, novelty, surprisingness, interestingness, and ambiguity. The second table shows the measure used to assess each collative variable in order to determine how Artificial Intelligence labelled would have a significant impact on the participants' aesthetic preference.

Table 2. Constructs, scale items and source

\begin{tabular}{l|l|l|l}
\hline \multicolumn{1}{c|}{ Construct } & Item coding & \multicolumn{1}{|c}{ Measurement } & Adapted from \\
\hline (a) complexity* & Q_COM & Rate the complexity of the painting & Berlyne (1971) \\
(b) novelty* & Q_NOV & Rate the novelty of the painting & \\
(c) surprisingness* & Q_SUP & I find the painting surprising & \\
(d) interestingness* & Q_INT & I find the painting interesting & \\
(e) ambiguity* & Q_AMB & Rate the ambiguity of the painting & \\
& & & \\
\hline
\end{tabular}

Notes: *seven-point Likert scale

First questions of each digitized colour abstract paintings designed to evaluate how complex is painting in the aesthetic preference. The novelty rate of the painting is the second question in the list, which followed by the next question about how the abstract painting surprises participants. Therefore, participants would follow the next question by referring to how they are interested in abstract painting. The final question purpose was to collect data for the ambiguity rate of the painting.

It was also decided to test accuracy for the validity of the collected data. It was tested by calculating the alpha of Cronbach and result was $(\alpha=0.79)$ higher than the standard 0.65 indexes (Steenkamp \& Geyskens, 2006). There was a positive correlation between the sections of each measure. 
Table 3. Normality and multicollinearity tests.

\begin{tabular}{llll}
\hline Item & Skewness & Kurtosis & VIF \\
\hline Q_COM & -0.19 & -0.25 & 1.23 \\
Q_NOV & -1.21 & 0.83 & 1.77 \\
Q_SUP & -0.18 & -0.88 & 2.21 \\
Q_INT & 0.34 & -0.85 & 1.58 \\
Q_AMB & 0.69 & 0.66 & 2.11 \\
Note: VIF = Variance inflation factor & & \\
\hline
\end{tabular}

However, as shown in the table 3, we checked for distribution normality and the absence of multicollinearity concerns. The objects in each parameter pose skewness and kurtosis values of \pm 2 , which have been assumed appropriate distribution normality indicators (Garson, 2012). Also, according to Hair et al. (1998), the variance inflation factor was below the recognised limit of 10 for each element (Table 2).

\section{RESULTS}

We first performed a comparison of the means between groups. As predicted, in response to complexity, interestingness and ambiguity questions, means of the control group is slightly higher (Fig. 1). However, ratings of novelty $(\bar{x}=4.31)$ and surprisingness $(\bar{x}=3.92)$ were significantly higher for works by AI than for works by the artist.

Figure 1. Descriptive statistics of the Experimental and Control Group

(by comparison of the means)

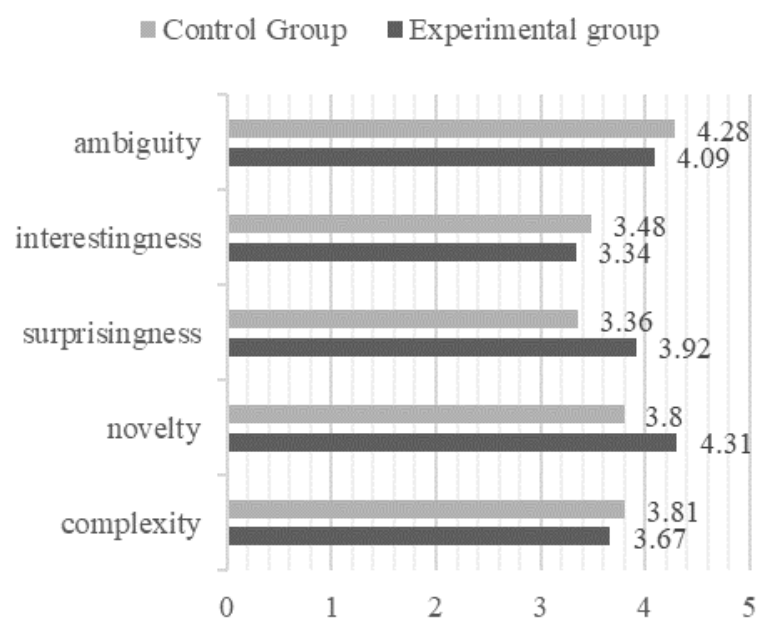

It was chosen to use ANOVA (analysis of variance) method to consider all the different conditions, to evaluate the impact on each dependent variable: complexity, novelty, surprisingness, interestingness, and ambiguity as you can see in Table 4.

To test H(a) complexity, which proposes that paintings with the Artificial Intelligence labelled as an author have a significant impact on the participants' aesthetic preference regarding the complexity rate of the abstract painting. According to the result of the analyses of between-group shows not significant statistic results, $(F(1,50)=0.59, p>0.45)$. 
However, ANOVA analysis of the second hypothesis $\mathrm{H}(\mathrm{b})$ indicates that there is a significant impact $(F(1,50)=6.16, p<0.02)$ on the participants' aesthetic preference regarding the novelty rate of the abstract painting. We carried out that participant in the experimental group found paintings more novel $(\bar{x}=4.31, s d=0.55)$ than the control group $(\bar{x}=3.80, s d=0.91)$. A further ANOVA analysis was performed to test $\mathrm{H}(\mathrm{c})$ surprisingness, and the results indicate that paintings labelled with Artificial Intelligence as an author were more surprising than original authors labelled as an artist. Consequently, $\mathrm{H}(\mathrm{c})$ is supported by $(F(1,50)=5.46$, $p<0.03)$ and experimental group mean result is $3.92(s d=0.89)$ while it is $3.36(s d=0.86)$ in the control group (Fig. 1.)

Table 4. Results of the hypotheses testing

\begin{tabular}{l|cc|c}
\hline \multirow{2}{*}{ Hypotheses } & \multicolumn{2}{|c|}{ ANOVA } & \multirow{2}{*}{ Results } \\
\cline { 2 - 3 } & $F(1,50)$ & $p$-value & Not Supported \\
\hline H(a) complexity & 0.59 & 0.45 & Supported \\
H(b) novelty & 6.16 & 0.02 & Supported \\
H(c) surprisingness & 5.46 & 0.03 & Not Supported \\
H(d) interestingness & 0.20 & 0.66 & Not Supported \\
H(e) ambiguity & 0.81 & 0.37 & \\
\hline
\end{tabular}

Contrary to our expectations regarding $\mathrm{H}(\mathrm{d})$ interestingness, we observe that there is no significant impact $(F(1,50)=0.20, p>0.66)$ on the participants' aesthetic preference while painting labelled Artificial Intelligence as an author in the title.

In terms of $\mathrm{H}(\mathrm{e})$ ambiguity, there are no statistical differences between experimental and control group that data do not support the last hypothesis $(F(1,50)=0.81, p>0.37)$.

\section{CONCLUSION AND FUTURE WORK}

We experimented with examining the effect on aesthetic judgments affected by the presence and awareness of the title of abstract paintings produced by Artificial Intelligence. We concentrated on how we view the quality of AI-generated art in our perception in terms of our ability to evaluate aesthetics, whether particular works of Abstract Painting have been created by artists or by Artificial Intelligence. Therefore, in our study, we followed Berlyne's psychobiological theory, which focuses on the role of arousal (complexity, novelty, surprisingness, interestingness, and ambiguity) as one of the primary factors of aesthetic preference.

The results of the study suggest that Artificial Intelligence as a title can have an impact on aesthetic judgments. Consequently, participants found abstract paintings more novel and surprising when Artificial Intelligence accompanied the title.

However, when participants were asked to evaluate the complexity, interestingness and ambiguity arousals of the paintings, the results did not show any statistic significant between the control and experimental group. Therefore, we assume that when "Artificial Intelligence" accompanied the title does not have any impact on our aesthetic preference regarding the complexity, interestingness and ambiguity.

Lastly, such results extend past studies by showing that the interpretation of the title influences the perception of the art by the participants. 
We could conclude that in terms of novelty and surprisingness arousals, the value of AIgenerated art in our perception shows significant differences from the same human-made art. Mostly, individuals find AI-generated art more surprising and newer, which could also impact their aesthetic preferences and judgment.

\subsection{Limitations and future works}

Regardless of the research's novelty, it has limitations that might be the motivation for future research. One of the main limitations was the number of participants and gender disbalance, which should be taken into account for more accurate results for future research. To take part in the experiment, it was not possible to reach more participants due to various course schedules at the university. Besides the quantity of the participants, participants' cultural and knowledge factors also could affect decision making while assessing the paintings.

Although in the field of psychology and arts the psychobiological model of Berlyn was beneficial, it also gave rise to criticisms, primarily because the connection between the collective variables and the hedonic value cannot always be implemented (Silvia, 2005; Jacobsen, 2006). Although, the collative model of Berlyne is not the only important theory of emotional responses to art. The most significant alternative of the collative theory is currently the model of prototypic aesthetic preferences (Martindale et al., 1990).

It will be exciting and relevant to replicate the research with various samples and painting styles, to find out whether there are obviously many differences that affect our aesthetic preferences and judgment.

\section{ACKNOWLEDGEMENT}

None of the artworks was modified, remixed, transformed while originality and authors remain the existing state of affairs in all levels of research except only during the experiment for the experimental group were applied these arts as made by Artificial Intelligence. Therefore, the experiment aimed to find out how individuals change their aesthetic preferences under different conditions. The author would like to thank all the authors of the abstract arts that we have such a fascinating painting as humanity.

In addition, the author would like to thank all lecturers and students of the Tbilisi State Academy of Arts (Georgia) for their contribution to this project. Besides, the author would like to thank three anonymous reviewers for providing their productive comments, which was influential in the progress of this article. 


\section{REFERENCES}

ALVAREZ, S., WINNER, E., HAWLEY-DOLAN, A. and SNAPPER, L. (2015). What Gaze Fixation and Pupil Dilation Can Tell Us About Perceived Differences Between Abstract Art by Artists Versus by Children and Animals. Perception, 44(11), pp.1310-1331.

BELKE, B., LEDER, H., STROBACH, T. and CARBON, C.C., (2010). Cognitive fluency: High-level processing dynamics in art appreciation. Psychology of Aesthetics, Creativity, and the Arts, 4(4), p.214.

BERLYNE, D. (1960). Conflict, arousal, and curiosity. New York, NY: McGraw-Hill.

BERLYNE, D.E., (1967). Arousal and reinforcement. In: D. Levine, (ed.), Nebraska symposium on motivation. Lincoln, NE: University of Nebraska Press.

BERLYNE, D. (1971). Aesthetics and psychobiology. New York: Appleton-Century-Crofts.

BERLYNE, D.E. (ed.), (1974). Studies in the new experimental aesthetics. Washington: Hemisphere.

BERLYNE, D.E. and OGILVIE, J.C., (1974). Dimensions of perception of paintings. Studies in the new experimental aesthetics, pp.181-226.

BUBIĆ, A., SUŠAC, A. and PALMOVIĆ, M., (2016). Observing individuals viewing art: The effects of titles on viewers' eye-movement profiles. Empirical Studies of the Arts, 35(2), pp.194-213.

CHAMBERLAIN, R., MULLIN, C., SCHEERLINCK, B. and WAGEMANS, J. (2018). Putting the art in artificial: Aesthetic responses to computer-generated art. Psychology of Aesthetics, Creativity, and the Arts, 12(2), pp.177-192.

CHMIEL, A. and SCHUBERT, E., (2017). Back to the inverted-U for music preference: A review of the literature. Psychology of Music, 45(6), pp.886-909.

CLEEREMANS, A., GINSBURGH, V., KLEIN, O. and NOURY, A., (2016). What's in a name? The effect of an artist's name on aesthetic judgments. Empirical Studies of the Arts, 34(1), pp.126-139.

COECKELBERGH, M., (2016). Can Machines Create Art?. Philosophy \& Technology, 30(3), pp.285-303.

COHN, G., (2018). AI Art at Christie's Sells for \$432,500. [online] Nytimes.com. Available at: https://www.nytimes.com/2018/10/25/arts/design/ai-art-sold-christies.html [Accessed 2 Nov. 2018].

COLTON, S., (2012). The painting fool: Stories from building an automated painter. In Computers and creativity (pp. 3-38). Springer, Berlin, Heidelberg.

COLTON, S., HALSKOV, J., VENTURA, D., GOULDSTONE, I., COOK, M. and FERRER, B.P., (2015). The Painting Fool Sees! New Projects with the Automated Painter. ICCC (pp. 189-196).

CUPCHIK, G.C., (1974). An experimental investigation of perceptual and stylistic dimensions of paintings suggested by art history. Studies in the new experimental aesthetics, pp.235257.

CUPCHIK, G.C., (1986). A decade after Berlyne: New directions in experimental aesthetics. Poetics, 15(4-6), pp.345-369. 
EISNER, E., (2002). The arts and the creation of mind. New Haven: Yale University Press.

ELGAMMAL, A. and SALEH, B., (2015). Quantifying creativity in art networks. arXiv preprint arXiv:1506.00711.

ELGAMMAL, A., Liu, B., ELHOSEINY, M. and MAZZONE, M., (2017). CAN: Creative adversarial networks, generating" art" by learning about styles and deviating from style norms. arXiv preprint arXiv:1706.07068.

FINSTAD, K., (2010). Response interpolation and scale sensitivity: Evidence against 5-point scales. Journal of Usability Studies, 5(3), pp.104-110.

FISHER, J., (1984). Entitling. Critical Inquiry, 11(2), pp.286-298.

FOSSA, F., (2017). Creativity and the Machine. How Technology Reshapes Language. Odradek Studies in Philosophy of Literature, Aesthetics, and New Media, 3(1-2), pp. 177-213,

GARSON, G.D., (2012). Testing statistical assumptions. Asheboro, NC: Statistical Associates Publishing.

GATYS, L.A., ECKER, A.S. and BETHGE, M., (2016). Image style transfer using convolutional neural networks. In Proceedings of the IEEE conference on computer vision and pattern recognition (pp. 2414-2423).

GERGER, G. and LEDER, H., (2015). Titles change the esthetic appreciations of paintings. Frontiers in Human Neuroscience, 9, p.464.

GOODFEllOW, I., POUGET-ABADIE, J., MIRZA, M., Xu, B., WARDE-FARLEY, D., OZAIR, S., COURVILLE, A. and BENGIO, Y., (2014). Generative adversarial nets. In Advances in neural information processing systems (pp. 2672-2680).

GRAMPP, W.D., (1989). Pricing the priceless: art, artists, and economics. New York: Basic Books.

HAIR, J.F., BLACK, W.C., BABIN, B.J., ANDERSON, R.E. and TATHAM, R.L., (1998). Multivariate data analysis. NJ: New Jersey: Prentice hall.

HAWLEY-DOLAN, A. and WINNER, E., (2011). Seeing the mind behind the art: People can distinguish abstract expressionist paintings from highly similar paintings by children, chimps, monkeys, and elephants. Psychological Science, 22(4), pp.435-441.

HERTZMANN, A., (2018). Can Computers Create Art?. Arts, 7(2), p.18.

HUSSAIN, F., 1(965). Quelques problèmes d'esthétique expérimentale. Sciencias de l'Art, 2, pp.103-114.

ISRAFILZADE, K. and PILELIENĖ, L., (2018). Can machines paint?. 5th International Multidisciplinary Scientific Conference on Social Sciences and Arts SGEM 2018, 18(6.3), pp. 109-116.

JACOBSEN, T., (2006). Bridging the arts and sciences: A framework for the psychology of aesthetics. pp.155-162.

KAKOUDAKI, D., (2014). Anatomy of a robot: Literature, cinema, and the cultural work of artificial people. New Brunswick, NJ: Rutgers University Press. 
KIRK, U., SKOV, M., HULME, O., CHRISTENSEN, M.S. and ZEKI, S., (2009). Modulation of aesthetic value by semantic context: An fMRI study. Neuroimage, 44(3), pp.11251132 .

LEDER, H., BELKE, B., OEBERST, A. and AUGUSTIN, D., (2004). A model of aesthetic appreciation and aesthetic judgments. British journal of psychology, 95(4), pp.489-508.

LEDER, H., CARBON, C.C. and RIPSAS, A.L., (2006). Entitling art: Influence of title information on understanding and appreciation of paintings. Acta psychologica, 121(2), pp.176-198.

LEVINSON, J., (1985). Titles. The Journal of Aesthetics and Art Criticism, 44(1), pp.29-39.

LÉVY, C.M., MACRAE, A. and KÖSTER, E.P., (2006). Perceived stimulus complexity and food preference development. Acta psychologica, 123(3), pp.394-413.

MARTINDALE, C. and MOORE, K., (1989). Relationship of musical preference to collative, ecological, and psychophysical variables. Music Perception: An Interdisciplinary Journal, 6(4), pp.431-445.

MARTINDALE, C., MOORE, K. and BORKUM, J., (1990). Aesthetic preference: Anomalous findings for Berlyne's psychobiological theory. The American Journal of Psychology, pp.53-80.

MULLENNIX, J.W. and ROBINET, J., (2018). Art expertise and the processing of titled abstract art. Perception, 47(4), pp.359-378.

NISSEL, J., HAWLEY-DOLAN, A. and WINNER, E. (2015). Can Young Children Distinguish Abstract Expressionist Art From Superficially Similar Works by Preschoolers and Animals?. Journal of Cognition and Development, 17(1), pp.18-29.

NOLL, A.M., (1966). Human or machine: A subjective comparison of Piet Mondrian's "Composition with Lines" (1917) and a computer-generated picture. The psychological record, 16(1), pp.1-10.

NUNEZ, G.A., (2019). Between Utopia and Dystopia: Contemporary Art and Its Conflicting Representations of Scientific Knowledge. Handbook of Popular Culture and Biomedicine (pp. 245-258). Springer, Cham.

OBVIOUS ART, (2018). Edmond de Belamy - Obvious Art. [online] Available at: https://obvious-art.com/edmond-de-belamy.html [Accessed 21 Feb. 2019].

PALMER, S.E., SCHLOSS, K.B. and SAMMARTINO, J., (2013). Visual aesthetics and human preference. Annual review of psychology, 64, pp.77-107.

PAN, Y. (2016). Heading toward Artificial Intelligence 2.0. Engineering, 2(4), pp.409-413.

PELOWSKI, M., MARKEY, P.S., LAURING, J.O. and LEDER, H., (2016). Visualizing the impact of art: An update and comparison of current psychological models of art experience. Frontiers in human neuroscience, 10, p.160.

RUSSELL, P.A. and MILNE, S., (1997). Meaningfulness and hedonic value of paintings: Effects of titles. Empirical Studies of the Arts, 15(1), pp.61-73.

SCHWAB, K. (2017). The fourth industrial revolution. New York: Crown Business.

SHAMIR, L., NISSEL, J. and WINNER, E. (2016). Distinguishing between Abstract Art by Artists vs. Children and Animals. ACM Transactions on Applied Perception, 13(3), pp.1-17. 
SILVIA, P.J., (2005). Emotional responses to art: From collation and arousal to cognition and emotion. Review of general psychology, 9(4), pp.342-357.

STEENKAMP, J.B.E. and GEYSKENS, I., (2006). How country characteristics affect the perceived value of web sites. Journal of marketing, 70(3), pp.136-150.

STEINERT, S., (2016). Art: Brought to You by Creative Machines. Philosophy \& Technology, 30(3), pp.267-284.

STOCK, M., (2019). Ai-Da, the humanoid robot artist, gears up for first solo exhibition. [online] U.S. Available at: https://www.reuters.com/article/us-tech-robot-artist/ai-dathe-humanoid-robot-artist-gears-up-for-first-solo-exhibition-idUSKCN1T6215 [Accessed 21 Jul. 2019].

VARNEDOE, K., (2006). Pictures of nothing: abstract art since Pollock. Princeton, NJ: Princeton University Press. 


\section{APPENDIX}

Appendix 1. Computer-generated picture research by A. MICHAEL NOLL' (1966)

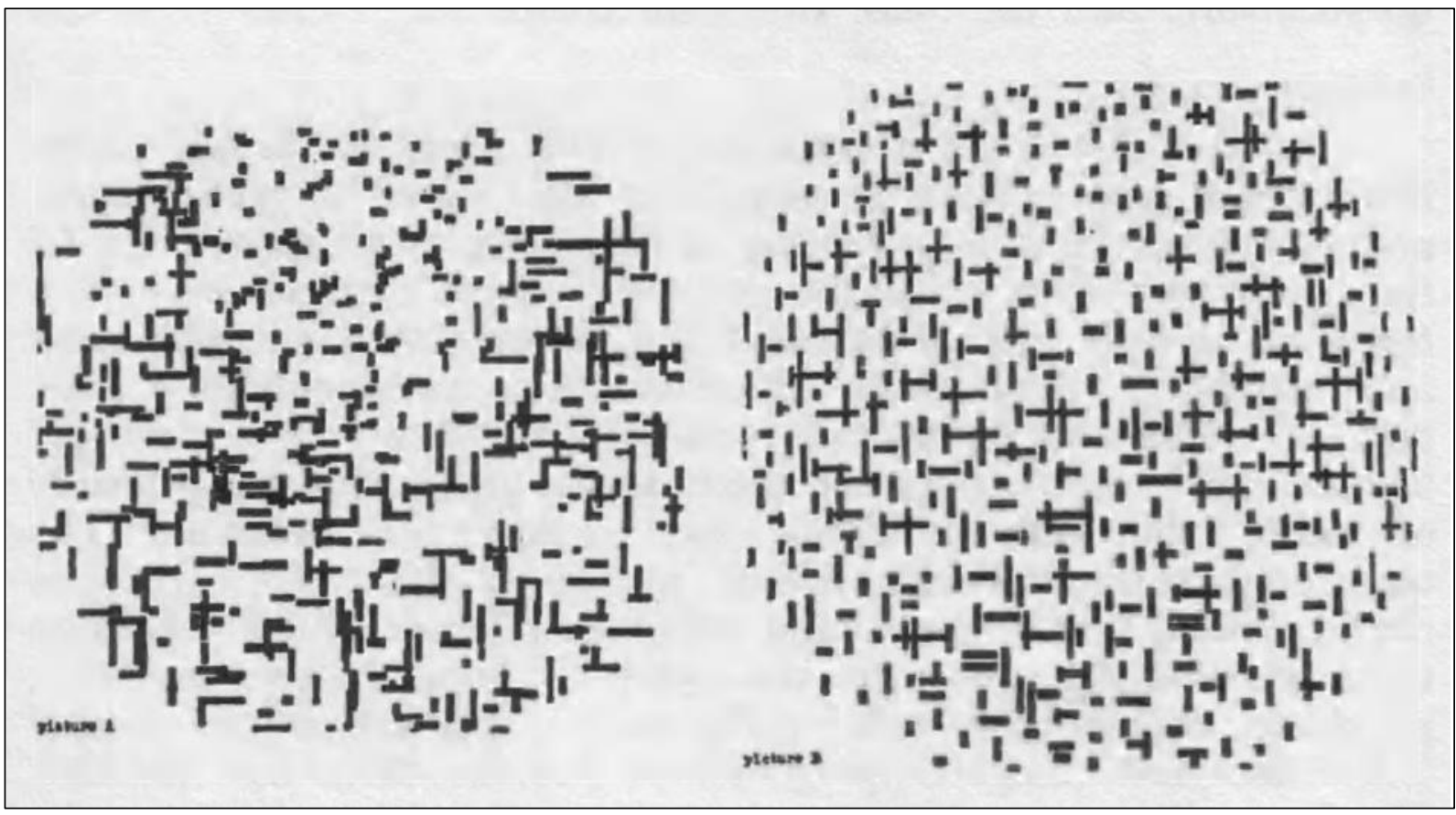

Left picture - "Computer Composition With Lines" (1964) by the author in association with an IBM 7094 digital computer and a General, Dynamics SC-4020 microfilm plotter. (CA. Michael Noll 1965).

Right picture - "Composition With Lines" (1917) by Piet Mondrian. (Reproduced with permission of Rijkmuseum Kroller-M idler, Otterlo, The Netherlands, (C Rijkmuseum KrollerMiiller.)

Appendix 2. List of abstract paintings used in the experiments:

Painting 1. "Houses of the Holy VI" Painting by STELLA MICHAELS / Wikimedia Commons/ (CC BY-SA 4.0)

Link:

https://commons.wikimedia.org/wiki/File:\%22Houses_of_the_Holy_VI\%22_Painting_by_Stel la_Michaels.jpg

Painting 2. " I Think of the Open Sea" Painting by JON SCHUELER Estate/ Wikimedia Commons/ (CC BY-SA 4.0)

Link:

https://commons.wikimedia.org/wiki/File:SchuelerEstate-

I_think_of_the_Open_Sea.jpg 
Painting 3. "Creating Mischief" Painting by TODD WILLIAMSON/ Wikimedia Commons/ (CC BY-SA 4.0)

Link:

https://commons.wikimedia.org/wiki/File:Todd_WILLIAMSON,_Creating_Mischief_(60x60in ),_Oil_on_canvas_(2016).jpg SA 4.0)

Painting 4. Painting by HENNY VAN SETTEN/ Wikimedia Commons/ (CC BY-

Link: https://commons.wikimedia.org/wiki/File:HvanSetten_C12.jpg

Painting 5. "Red Sea IV" Painting by STELLA MICHAELS/ Wikimedia Commons/ (CC BY-SA 4.0)

Link:

https://commons.wikimedia.org/wiki/File:\%22Red_Sea_IV\%22_Painting_by_Stella_Michael s.jpg 